\title{
Recognition of common odors, pictures, and simple shapes
}

\author{
HARRY T. LAWLESS \\ Walter S. Hunter Laboratory of Psychology, Brown University, Providence, Rhode Island 02912
}

\begin{abstract}
Recognition of common odors and simple shapes decayed in a similar manner over the course of 4 months. Recognition of complex pictures was uniformly higher than recognition of the odors and simple figures, although the distractors for these stimuli were much less similar than for the odors or simple shapes. Recognition of these common odors was the same as recognition performance on single chemicals used in previous studies. These results suggest that simple chemicals and complex familiar odors are encoded or remembered in a similar fashion, and that visual stimuli exist which are encoded in a similar manner to odors, possibly as unitary images with few features.
\end{abstract}

Comparisons of recognition memory for visual and olfactory stimuli have drawn attention to differences in the forgetting functions in the two modalities (Engen \& Ross, 1973; Lawless \& Cain, 1975). For example, Shepard (1967) found memory for pictures to decay from $100 \%$ correct recognition to near chance performance in 4 months. In contrast, Engen and Ross (1973) and Lawless and Cain (1975) found imperfect acquisition of odors in recognition tasks, but relatively little loss over time. However, these studies differ in other important variables in addition to the modality of presentation, notably the number of stimuli and presentation rate. Stimulus set size affects odor recognition (Engen \& Ross, 1973). Both exposure time and interstimulus interval affect visual recognition (Shaffer \& Shiffrin, 1972; Weaver, 1974). Only Davis (1977) equated these variables. He found recognition of simple shapes to be superior to odor recognition after a delay of 7 days. The stimuli differed, however, in acquisition level and distractor-target similarity.

In general, the question arises as to whether the differences found in the forgetting functions are due to the modality of presentation, to other characteristics of the stimuli, or to differences in procedure between experiments. One purpose of this study was to provide a within-subject comparison of recognition memory for odors and visual stimuli, equating presentation rate and number of stimuli. Longer test intervals than Davis's were used, and an attempt was made to equate distractor-target similarity. Simple figures were presented which are processed in a similar manner to odors. Clark (1965) found no effect of time delay or of verbal codability on recognition, and subjects re-

This experiment was performed while the author held a Graduate Fellowship from the National Science Foundation. The author thanks William $S$. Cain for helpful suggestions. Reprint requests should be sent to Harry Lawless, U.S. Army Natick Research and Development Command, Food Sciences Laboratory, Natick, Massachusetts 01760. ported coding the simple figures in a holistic fashion. These are characteristics of odor memory found in subsequent studies (Engen \& Ross, 1973; Lawless \& Cain, 1975).

A second purpose of this study was to investigate recognition memory for common household odors. Previous studies have used single chemical compounds. Subjects can accurately identify far more common complex odors than they can identify simple chemicals (Desor \& Beauchamp, 1974; Engen \& Pfaffmann, 1960). Cain (1977) suggested that identification is predicated upon the ability to recognize a stimulus. The question arises as to whether the advantage enjoyed by common odors in the associational task would be observed in recognition tests. Such an advantage would question the generality of previous findings in odor memory and would argue for an associational component in recognition (Underwood, 1974).

\section{METHOD}

\section{Subjects}

Sixty-six subjects of college age volunteered. They were informed that it was a memory experiment, and that they would be tested at a later date.

\section{Stimuli}

One set of 24 visual stimuli consisted of $10 \times 15 \mathrm{~cm}$ fullcolor pictures clipped from a travel magazine. A second set of 24 visual stimuli were the free forms shown in Figure 1. They were generated on a CalComp plotter from the equation

$$
r(\theta)=\sum_{n=1}^{6} \exp \left[W_{n} N\left(\theta-\theta_{n}\right)\right]
$$

where $W_{n}$ was a weighting coefficient and $\theta_{n}$ was the offet angle of the $n^{\text {th }}$ harmonic. A complete discussion of the psychological properties of these figures can be found in Shepard and Cermak (1973). The 24 common odors were coffee, paint, honey, chocolate, aftershave, Pine-sol, maple syrup, beer, cat litter, mothballs, peanut butter, hand soap, cheddar cheese, 


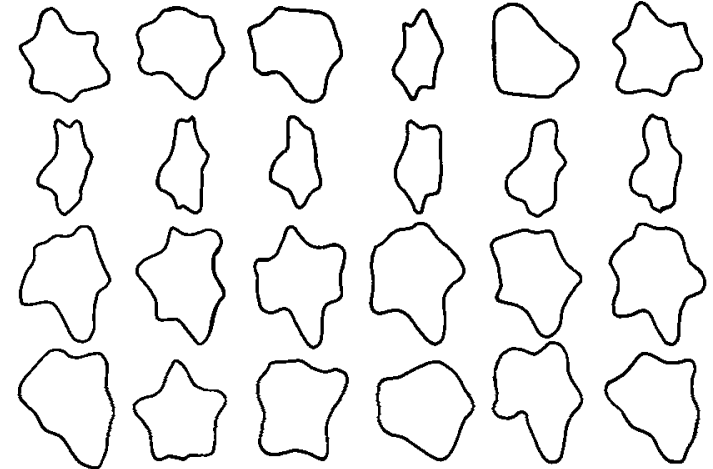

Figure 1. The 24 free-form stimuli. Original size, approximately $20 \times 25 \mathrm{~cm}$.

fish, lemon, Chlorox bleach, cigars, vinegar, rye whiskey, cinnamon, perfume, onion, oregano, and shoe polish. They were presented in $45 \times 55 \mathrm{~mm}$ jars with caps. The inspection sets of 12 stimuli were randomly selected from the larger sets of 24 . The remaining 12 stimuli served as distractors in a two-alternative forced-choice test.

\section{Procedure}

Six subjects rated the similarity of stimuli within each set of 24. They inspected standard stimuli drawn at random from each set. The subjects then judged the similarity of each standard to each of the 24 stimuli in the set using a scale of 0 to 100 (100 representing identity and 0 representing maximum dissimilarity). The standards were re-presented after every 4th stimulus. The subjects closed their eyes while inspecting the odors. Each subject made two sets of 24 judgments to odor, picture, and free-form standards.

The other 60 subjects inspected sets of 12 odors, 12 pictures, and 12 free forms. The presentation rate was $2 \mathrm{stimuli} / \mathrm{min}$. The order of presenting the different sets was counterbalanced. The subject sat in a well-lighted booth equipped with exhaust fans. The experimenter sat outside the booth and held up the visual stimuli in front of a window, and passed the odors through a small portal. While inspecting the odors, the subjects closed their eyes.

During the presentation (or after, in the case of the odors), the subjects rated the familiarity of the stimuli on a 7-point scale. For the free forms, the subjects were asked to mark the stimuli as familiar if the form reminded them of anything and unfamiliar if nothing came to mind. In this case, the familiarity scale was used as an index of the associative value of the forms.

Recognition was tested $20 \mathrm{~min}, 7$ days, 4 weeks, or 4 months after inspection. Each subject took a two-alternative forcedchoice test on all 36 stimuli that were originally presented, but at only one of the intervals.

\section{RESULTS AND DISCUSSION}

As shown in Figure 2, the forgetting curves for the odors and free forms flattened out after a drop in performance of $15 \%$ during the first month. In contrast, performance on the pictures remained at $100 \%$ during the first month, but dropped to $81 \%$ correct recognition at 4 months. An analysis of error scores revealed that these changes over time were significant $[\mathrm{F}(3,56)=19.5$, $\mathrm{p}<.001]$. The differences among the stimulus sets were also significant $[F(2,112)=62.5, p<.001]$, as was the interaction of time with stimulus type $[\mathrm{F}(6,112)=2.4$, $p<.05]$. However, the forgetting functions of the odors and free forms were roughly parallel, as shown by a nonsignificant interaction between these two sets $[F(3,56)<1]$. Futhermore, functions for exponential decay were fit to these curves, and gave similar rate constants of $1.68 \times 10^{-2}$ for odors and $1.11 \times 10^{-2}$ for free forms $(\mathrm{r}=.86$ and .68 , respectively).

The relationship of recognition performance of visual and olfactory stimuli clearly depends upon the visual stimuli to which the odors are compared. Given the flexibility of the visual system, it is not surprising that stimuli could be constructed which show similar forgetting curves to those typical of odors. Other similarities exist for recognition memory for odors and simple figures, namely independence from verbal coding and little or no effect of time in short-term tasks (Cermak, 1971; Clark, 1965; Engen, Kuisma \& Eimas, 1973; Lawless \& Cain, 1975). The similarity in the forgetting curves found in this study may be due to similar encoding strategies. Engen and Ross (1973) suggested that odors might be encoded in a unitary or holistic fashion, i.e., with few component features. and that this led to limited acquisition, but little loss over time. Clark (1965) reported that subjects relied on remembering images of the whole contour of simple forms. This was in contrast to more complex visual stimuli, where verbal codes and associations were often employed.

The differences among recognition scores on the different stimulus sets could be related to the similarity of the distractors (Engen \& Ross, 1973). The relationship of judged similarity to recognition was recently explored by Jones, Roberts, and Holman (1978) for the odors of common spices. They found that multidimensional scaling of a similarity judgment matrix and a confusion matrix from recognition tests gave highly similar solutions. In this study, the pictures, which had the highest recognition scores also had significantly lower intralist similarity than odors or free forms ( $t$ tests, $p<.01)$. The intralist similarity ratings averaged 32.0 for pictures, 40.6 for odors, and 43.8 for free forms (SEM $=1.59,1.60$, and 1.68, respectively).

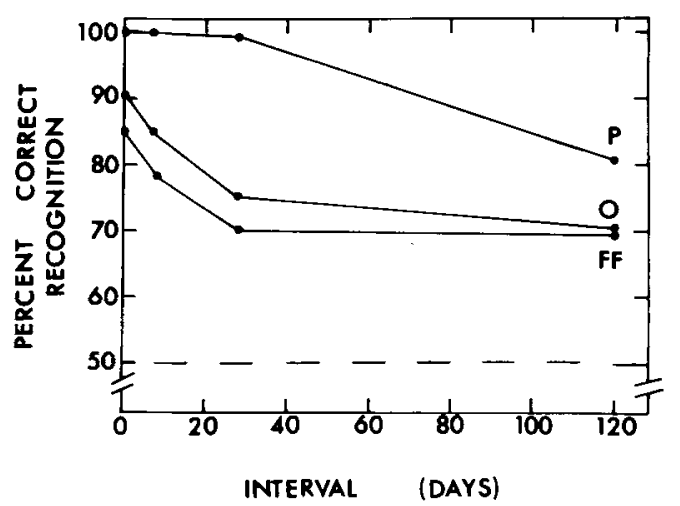

Figure 2. Recognition performance on the pictures (P), odors (O), and free-form stimuli (FF). Chance $=50 \%$ 
New associations are more easily learned to familiar codable odors than to unfamiliar odors in paired-associate tasks (Davis, 1975). Complex common odors are more easily named than single chemicals in absolute identification tasks (Desor \& Beauchamp, 1974; Engen \& Pfaffmann, 1960). However, such odors show no advantage in a recognition task. Performance on these common household odors may be compared to the data of Lawless and Cain on recognition of single chemicals (similar presentation rates and numbers of stimuli were used). The mean percent correct recognition was 91,85 , and 76 in this study, as compared with 86,84 , and 76 for single chemicals, for the immediate 1-week, and 4-week delays, respectively. An analysis of variance (after arcsin transformation of percent correct) showed no difference between the studies $[F(1,99)=1.43]$, but a significant effect of time $[F(2,99)=10.43, p<.001]$.

As noted previously (Engen \& Ross, 1973; Lawless $\&$ Cain, 1975), there was no effect of rated stimulus familiarity on recognition. There were no differences in the familiarity ratings of stimuli that were recognized and stimuli that were missed ( $t$ tests, $p>.1)$. This lack of a familiarity effect, in addition to the lack of difference between recognition of simple chemicals and complex codable odors, indicates that odor recognition may be mediated by associations within the experimental context rather than previous "background" associations (see Underwood, 1971, 1974). This is consistent with the observation that novel odors are often easily recognized in these tasks (Engen \& Ross, 1973) since their only association would be to the experimental context. The relative independence of odor recognition from previous associations is evidenced by the tip-of-the-nose phenomenon, in which an odor is judged to be very familiar, but specific associations, such as the odor's name, cannot be retrieved (Lawless \& Engen, 1977).

\section{REFERENCES}

CaIN, W. S. Physical and cognitive limitations on olfactory processing in human beings. In D. Muller-Schwarze \& M. Mozell (Eds.), Chemical communication in vertebrates. New York: Plenum Press, 1977.
Cermak, G. W. Short-term recognition memory for complex free-form figures. Psychonomic Science, 1971, 25, 209-211.

CLARK, H. J. Recognition memory for random shapes as a function of complexity, association value and delay. Journal of Experimental Psychology, 1965, 69, 590.595.

DAvis, R. G. Acquisition of verbal associations to olfactory stimuli of varying familiarity and to abstract visual stimuli. Journal of Experimental Psychology: Human Learning and Memory, 1975, 104, 134-142.

DAvis, R. G. Acquisition and retention of verbal associations to olfactory and abstract visual stimuli of varying similarity. Journal of Experimental Psychology: Human Learning and Memory, 1977, 3, 37.51.

Desor, J. A., \& Beauchamp, G. K. The human capácity to transmit olfactory information. Perception \& Psychophysics, 1974, 16, 551-556.

Engen, T., Kuisma, J. E., \& Eimas, P. D. Short-term memory of odors. Journal of Experimental Psychology, 1973, 99, 222-225.

Engen, T., \& Praffmann, C. Absolute judgments of odor quality. Journal of Experimental Psychology, 1960, 59, 214-219.

ENGEN, T., \& Ross, B. M. Long-term memory of odors with and without verbal descriptions. Joumal of Experimental Psychology, 1973, 100, 221-227.

Jones, F. N., Roberts, K., \& Holman, E. W. Similarity judgments and recognition memory for some common spices. Perception \& Psychophysics, 1978, 24, 2-6.

Lawless, H. T., \& CaIN, W. S. Recognition memory for odors. Chemical Senses and Flavor, 1975, 1, 331-337.

LAWLESS, H. T., \& ENGEN, T. Associations to odors: Interference, mnemonics, and verbal labeling. Journal of Experimental Psychology: Human Learning \& Memory, 1977, 3, 52-59.

Shaffer, W. O.. \& Shiffrin, R. M. Rehearsal and storage of visual information. Journal of Experimental Psychology, 1972, 92, 292.296.

ShePARD, R. N. Recognition memory for words, sentences and pictures. Journal of Verbal Learning and Verbal Behavior, $1967,6,156-163$.

Shepard, R. N., \& Cermak, G. W. Perceptual-cognitive explorations of a toroidal set of free-form stimuli. Cognitive Psychology, $1973,4,351-377$.

UNDERWOOD, B. J. Recognition memory. In H. H. Kendler \& J. T. Spence (Eds.), Essays in neo-behaviorism. New York: Appleton-Century-Crofts, 1971.

UNDERWOOD, B. J. The role of association in recognition memory. Journal of Experimental Psychology, 1974, 102, 917-939.

WEAVER, G. E. Effects of poststimulus study time on recognition of pictures. Journal of Experimental Psychology, 1974, 103, 799-801.

(Received for publication June 26, 1978; revision accepted August 5, 1978.) 